\section{International Scientific Journal Theoretical \& Applied Science}

p-ISSN: 2308-4944 (print) e-ISSN: 2409-0085 (online)

Year: $2015 \quad$ Issue: $12 \quad$ Volume: 32

Published: $30.12 .2015 \quad$ http://T-Science.org
Nikolay Vasilevich Penshin candidat of economic sciences, Head of the Department "Organization of transportation and road safety" Tambov state technical University, Russia avtobd@mail.ru

Victor Yurievich Ivlev

Undergraduate, Mechanical engineer Aor Nekrasovskoe RTP, city of Rasskazovo, Russia victor.pshenihniy_7@mail.ru

SECTION 27. Transport.

\title{
THE DRIVER OF THE XXI CENTURY. INNOVATIVE TEACHING METHODS
}

Abstract: The article reveals the problems of the Commission of the driver, and the introduction of innovative teaching methods.

Key words: The driver, road environment, teaching methods.

Language: Russian

Citation: Penshin NV, Ivlev VY (2015) THE DRIVER OF THE XXI CENTURY. INNOVATIVE TEACHING METHODS. ISJ Theoretical \& Applied Science 12 (32): 96-98.

Soi: http://s-o-i.org/1.1/TAS-12-32-18 Doi: crossef http://dx.doi.org/10.15863/TAS.2015.12.32.18

УДК 502.7

\section{ВОДИТЕЛЬ ХХІ ВЕКА. ИННОВАЦИОННЫЕ МЕТОДЫ ОБУЧЕНИЯ}

Аннотация: В статье раскрываются проблемы обучения водителя, и внедрение инновационных методов подготовки.

Ключевые слова: Водитель, дорожная среда, методы обучения.

В XXI веке водитель должен знать много по вождению автомобиля, постоянно совершенствоваться со временем. Водитель должен быть осведомлен, какими законами, правилами и постановлениями регулируется дорожное движение, а также что несет за собой нарушение данных правил. Каждый водитель просто обязан знать правила дорожного движения, также негласные различные негласные особые правила, которые нужно соблюдать хорошему водителю.

Опытным водителям известно, что не всегда получается соблюдать официальные ПДд, но при этом важно не мешать движению на дороге. Уступать дорогу, где есть необходимость, просчитывать ситуацию на несколько шагов вперед, не прибавлять скорость, когда обгоняют краткий перечень тех правил, которыми руководствуются нормальные водители.

Официально нет такого перечня, который рассказал бы, какими качествами должен обладать водитель. Всем известно, что настоящий водитель должен быть профессионалом своего дела - знать правила дорожного движения, ориентироваться на местности, необходимо иметь также стойкое психическое здоровье, отличное зрение и реакцию. Это поможет избежать негативных ситуаций на дороге.

А также в дороге важно терпение. Оно точно пригодится в пробках, при общении с сотрудниками дорожно-патрульной службы и в иных ситуациях. Кроме того, водитель обязательно поможет в пути любому другому водителю, попавшему в беду или не справившемуся с экстремальными условиями вождения.

У водителя XXI века должен сконструировать салон автомобиля, который должен быть насыщен электроникой. Например боковое зеркало, заменено телекамерой, с которой поступает информация о транспортной обстановке не только сзади, но и с обеих сторон машины. Радарная установка позволит свободно ехать при почти «нулевой» видимости ночью и в туман. У водителя XXI века в кабине должны быть приборы, регистрирующие состояние дорожного покрытия, коэффициент сцепления и температуру воздуха. Все эти данные автоматически передаются на ЭВМ, которая задаст автомашине оптимальную скорость. Специальная гидравлическая система позволит водителю избежать травм, в случае аварии она моментально выбрасывает кабину наверх. 
В современном мире очень тяжело быть водителем: бесконечные пробки на дорогах, некачественные автомобили. В XXI веке бесконечное множество опасных соблазнов. Это алкоголь, наркотики и т.д. И человек не редко попробовав такой соблазн садиться за руль. При этом страдает не только водитель, но и пассажиры и пешеходы. Несоблюдение правил дорожного движения тоже одна из причин автотранспортных происшествий. Ведь каждый день на дорогах погибают сотни человек и тысячи попадают в больницу. В том числе и дети, водитель должен всегда помнить об этом.

Отметим, что из-за несовершенства транспортных систем безопасности на дорогах в настоящее время гибнет людей больше чем в локальных военных конфликтах, и поэтому необходимо инновационные методы обучения водителя.

В Российской Федерации в результате транспортных происшествий погибают или получают ранения свыше 255 тыс. человек. На дорогах за последние девять лет погибли 9552 ребенка в возрасте до 16 лет, травмированы 209323 ребенка. Демографический ущерб от дорожно-транспортных происшествий и их последствий за 2012 - 2014 годы составил 571307 человек. [5, с. 74].

Размер экономического ущерба от дорожных происшествий, а также и их последствий за 2012 - 2013 годы оценивается в 8188,3 млрд. рублей, что можно сопоставлять с доходами консолидированных бюджетов субъектов Российской Федерации за 2012 год (8064,3 млрд. рублей).

В 2012 году экономический ущерб от дорожно-транспортных происшествий снизился до 862 млрд. рублей. [5, с. 78]. Обеспечение безопасности дорожного движения является составной частью задач обеспечения личной безопасности, а также решения демографических, социальных, и конечно экономических проблем, повышения качества жизни и содействия региональному развитию.

На графике представим данные за 2013-2014 гг. Как видно из графика цифры резко изменились в сравнении с 2013 и 2014 гг., в 2013 г. в России погибло 27953 человек, в 2014 28991. [5, с. 74].

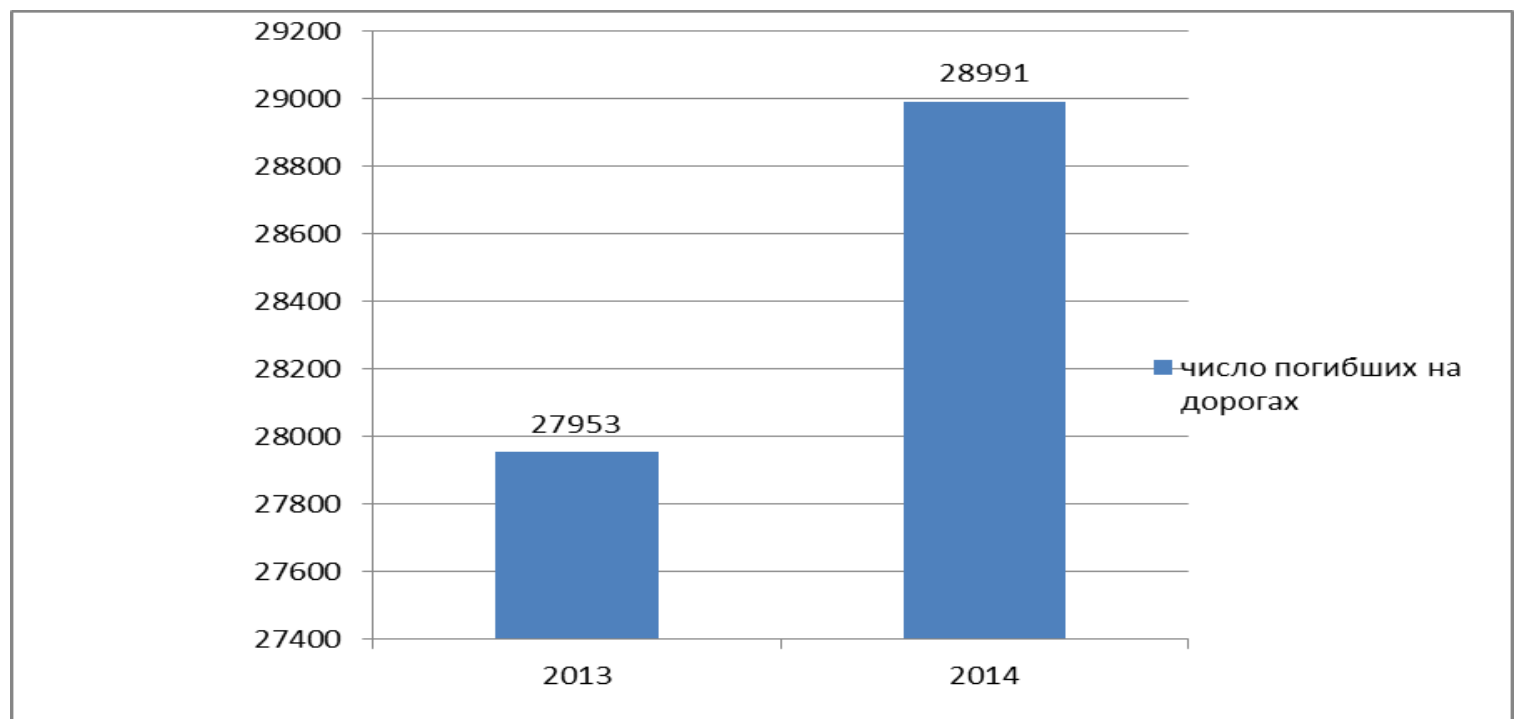

Рисунок 1 - Количество погибших на дорогах России.

В настоящее время водители пользуются инновационными техническими средства в организации дорожного движения. К инновационным техническим средствам относится, визуализация дорожных знаков в транспортном средстве. Данное изобретение относится к способам и устройствам для отображения дорожной информации. Кроме этого изобретение относится к области информационного обеспечения водителей транспортных средств, а также к приборам для конкретной индикации, а так же для появления записи и формирования сигнала, вернее сказать к способам визуального представления информации о показаниях устройств дорожнотранспортного средства. [4, с. 190].

Отметим, что из-за несовершенства транспортных систем безопасности на дорогах в настоящее время гибнет людей больше чем в локальных военных конфликтах. В настоящее время автомобильные дороги полностью загружены, пробки на дорогах постоянно, поэтому и тема в данное время актуальна. Отметим, что известны способы, когда с целью предупредить об опасной ситуации на автомобильных дорогах, на транспортное 
средство устанавливается приемное устройство, которое отображает состояние дорожного знака.

В настоящее время актуальным, являются инновационные методы обучения водителя. Если водитель считает что, научившись перемещать автомобиль с одного места на другое, постигли все премудрости науки управления автомобилем, то это конечно не так. Настоящее мастерство проверяется в экстремальных ситуациях, с которыми сталкивался практически каждый водитель, но не каждый справился. Поэтому необходимо показать, что такое опытный водитель на дороге. мастерство управления автомобилем. В самом общем виде его можно представить как сумму трех слагаемых (табл. 1).

\section{Уровни обучения водителей.}

Таблица 1

\begin{tabular}{|l|l|l|}
\hline $\begin{array}{l}\text { Базовые навыки управления } \\
\text { автомобилем }\end{array}$ & $\begin{array}{l}\text { Навыки ориентации в дорожном } \\
\text { движении }\end{array}$ & $\begin{array}{l}\text { Навыки управления автомобилем в } \\
\text { сложных и критических ситуациях }\end{array}$ \\
\hline Посадка за рулем & Наблюдение за дорожно- \\
Пуск двигателя & транспортной обстановкой \\
Начало движения & Прогнозирование возможных & В сложных дорожных и погодных \\
Переключение передач & опасностей & При поломке автомобиля \\
Торможение и остановка & Выбор скорости, траектории \\
Развороты, повороты, парковка, & движения, взаимодействие с & Вритических условиях \\
движение задним ходом & другими участниками движения & \\
\hline
\end{tabular}

Первая составляющая включает навыки, овладев которыми можно быстро и правильно передвигаться на автомобиле в условиях, когда другие участники движения не мешают. Проще говоря, когда их нет. Владение этими навыками надо довести до автоматизма. Только после этого можно переходить ко второй составляющей, в которую входят навыки, необходимые для безопасного движения. Здесь потребуется не только хорошая координация движения рук и ног, но главное - умение заранее выявлять возникающие на дороге опасности защищаться от них. Освоив эти навыки, вы подниметесь на вторую ступень мастерства. Третья ступень самая сложная. Поднявшись на нее, вы сможете защитить себя от любых неожиданностей, связанных с автомобилем, дорогой, погодой и т.д.

Обучение водителей необходимо совершенствовать на сложных тренажёрах (электронных с использованием компьютеров) для приобретения навыков решения ситуационных задач и навыков управления транспортными средствами в простых, сложных и аварийных ситуациях.

Специальная контраварийная подготовка на специально подготовленных площадках или автодроме.

Если на пути встретились тяжёлые участки или препятствия, необходимо прежде всего найти объезд. Если объезд невозможен, то нужно ознакомиться с состоянием трудно проходимого участка и принять необходимое решение.

Короткие участки с песчаным или мягким грунтом преодолеваются "с разгона", длинные -на низшей передаче. На песчаном грунте нельзя переключать передачи, так как в момент выключения сцепления сопротивление качению настолько повысится, что автомобиль сразу же остановится. Мокрые глинистые участки следует по возможности объезжать, в противном случае двигаться на низшей передаче и на малой скорости, не допуская резкого вращения рулём.

\section{References:}

1. Babkov VF (2012) road [Text] : textbook for high schools / V. F. Babkov. - Moscow: Transport, 2012. $-280 \mathrm{p}$.

2. Linevsky DS (2011) Psychology of safe driving. - Moscow: Norma, 2011 - pp. 289.

3. Malyshko TN (2012) Psychology novice driver. - Moscow: "Mahaon", 2012 - pp. 89.

4. Mishurin VM, Romanov AN (2012) The reliability of the driver and traffic safety / Moscow: Transport, 2012 - pp. 109.

5. Nemchinov MV (2014) once again about the quality // of the road No. 2, 2014. pp. 74-77.
6. Litvinov AS (2012) Car. Theory of operating properties [Text] / A. S. Litvinov, J. E. Farobin - Moscow: Transport, 2012 - pp. 289.

7. (2013) Log. Roads of Russia of the 21st century. 4/2013, $98 \mathrm{p}$.

8. Nemchinov MV (2014) again about the quality of // a road No. 2, 2014. pp. 74-77.

9. (2006) The Procedural, N. In. Road transport in the conditions of market economy-Ki / N. In. The procedural // Tambov state technical University. 2006. Vol. 12, No.2 A. pp. 448-457.

10. (2012) The Y. I. Zapolsky Architecture-vehicleroad. Moscow: Transport. 2012. - 190 p. 